\title{
$\mu$-X-ray fluorescence and $\mu$-X-ray diffraction investigations of sediment from the Ruprechtov nuclear waste disposal natural analog site
}

\author{
Melissa A. Denecke ${ }^{\mathrm{a}, *}$, Wout De Nolf ${ }^{\mathrm{b}}$, Koen Janssens ${ }^{\mathrm{b}}$, Boris Brendebach ${ }^{\mathrm{a}}$, André Rothkirch ${ }^{\mathrm{c}}$, \\ Gerald Falkenberg ${ }^{\mathrm{c}}$, Ulrich Noseck ${ }^{\mathrm{d}}$ \\ ${ }^{a}$ Forschungszentrum Karlsruhe, Institut für Nukleare Entsorgung, P.O. Box 3640, D-76021 Karlsruhe, Germany \\ ${ }^{\mathrm{b}}$ Department of Chemistry, University of Antwerp, Universiteitsplein 1, B-2610 Antwerp, Belgium \\ ${ }^{\mathrm{c}}$ Hamburger Synchrotronstrahlungslabor (HASYLAB) at DESY, Notkestr. 85, D-22603 Hamburg, Germany \\ ${ }^{\mathrm{d}}$ Gesellschaft für Anlagen- und Reaktorsicherheit (GRS) mbH, Theodor-Heuss-Straße 4, D-38122 Braunschweig, Germany
}

Received 10 July 2007; accepted 2 January 2008

\begin{abstract}
Results from combined $\mu-\mathrm{XRF}$ and $\mu-\mathrm{XRD}$ investigations of a uranium-rich tertiary sediment from a nuclear repository natural analog site in Ruprechtov, Czech Republic, are reported. The goal of the investigations is to identify arsenopyrite from diffraction patterns obtained in As-rich areas of the sample. Arsenopyrite has been revealed to be present in the sediment as thin coatings on the surface of Fe nodules from previous $\mu$ XANES results and observed linear dependencies between $\mathrm{Fe}$ and $\mathrm{As}(0)$ distributions obtained from $\mu$-XRF measurements. In thin sections of the sediment investigated here we find, however, neither diffraction reflections expected for arsenopyrite nor for other As-sulfides. The As( 0$)$ phase is likely present in the form of very small grains, or it is amorphous. Statistical analysis of the $\mu$-XRD data using unsupervised classification and principle component analysis from selected sample areas also indicate that pyrite and siderite, but no arsenopyrite, are the sole diffracting phases. That pyrite and siderite are found in the same sample is an indication that the $\mathrm{pH}$ of the sediment environment during diagenesis must have been neutral. This allows us to refine our hypothesis for the mechanism of uranium immobilization.
\end{abstract}

(C) 2008 Elsevier B.V. All rights reserved.

Keywords: Microfocus; Natural analog; $\mu$-XRD; $\mu$-XRF

\section{Introduction}

We perform spatially resolved X-ray fluorescence and diffraction investigations using a focused synchrotron beam with micrometer dimensions ( $\mu$-XRF and $\mu$-XRD) on a uranium-rich sediment originating from an aquiferous clay/lignite sediment with an anomalously high uranium concentration found in a nuclear waste disposal natural analog site located in the northwest of the Czech Republic [1-4]. The overall aim of such natural analog investigations is to assess immobilization mechanisms

\footnotetext{
* Corresponding author. Tel.: +49 7247 825536; fax: +49 7247823927.

E-mail addresses: melissa@ine.fzk.de (M.A. Denecke), wout.denolf@ua.ac.be (W. De Nolf), koen.janssens@ua.ac.be (K. Janssens), boris.brendebach@ine.fzk.de (B. Brendebach), andre.rothkirch@desy.de (A. Rothkirch), falkenbe@mail.desy.de (G. Falkenberg), Ulrich.Noseck@grs.de (U. Noseck)
}

leading to actinide enrichment. This provides a top-down approach to deal with the long time scales important for repository safety assessment, a near geological time domain spanned by the elevated radiotoxicity levels of a high level nuclear waste repository. Through understanding the immobilization mechanism in this time domain we can improve the predictive capabilities of safety assessment models and/or help improve concepts for intelligent barriers in the multi-barrier containment principle of a waste repository [5].

The present work is a continuation of previous micro-focused $\mathrm{X}$-ray investigations on the same sediment [6-8]. Results from these previous studies allow us to formulate a hypothesis for one mechanism of $U$ immobilization during diagenesis of the sediment involving arsenopyrite, AsFeS, as reducing agent. In this mechanism $U$ dissolved from nearby weathered granite is groundwater-mobile as a $\mathrm{U}(\mathrm{VI})$ species. The $\mathrm{U}(\mathrm{VI})$ migrates to a 
deeper, anoxic horizon with an underlying low-permeable kaolin layer and is reduced on arsenopyrite in the sediment, leading to precipitation of less-soluble U(IV). The arsenopyrite has been identified from its As K-edge X-ray absorption near edge structure (XANES) signature [6] and the observed linear dependence between $\mathrm{Fe}$ and $\mathrm{As}(0)$ distributions obtained from $\mu$-XRF measurements on As-rich coatings on the surface of sediment framboidal Fe nodules [7]. The $\mu$-XRF and $\mu$-XRD investigations reported here aim at securing evidence of arsenopyrite in the sediment from its diffraction pattern.

\section{Experimental section}

Measurements with focused beam are performed at the Beamline L experimental station at the Hamburger Synchrotronstrahlungslabor (HASYLAB) using synchrotron light from the DORIS storage ring operating at $4.436 \mathrm{GeV}$ with ring currents between 85 and $150 \mathrm{~mA}$. A new Mo/Si multilayer pair (lattice spacing $2.98 \mathrm{~nm}, 100$ layers, energy resolution $\Delta \mathrm{E} / \mathrm{E} \sim 1 \%$, AXO Dresden GmbH, Germany) is used to select a band pass of wavelengths from the white light coming from the DORIS ring bending magnet. This multilayer selects a smaller range of wavelengths but provides similar flux at an energy of $18 \mathrm{keV}$ used throughout the experiment as compared to the $\mathrm{Ni} / \mathrm{C}$ multilayers available at Beamline L [9]. The incident radiation is focused with an elliptical single-bounce monocapillary (CHESS; [10]) mounted on a hexapod positioning unit. The beam footprint on the sample delivered by the monocapillary is approximately $15 \mu \mathrm{m}$ at $18 \mathrm{keV}$ incident beam energy and $45^{\circ}$ orientation of the sample to the incident beam. The sample is mounted on an $x, y$ positioning stage to scan in a step-by-step (i.e., pixel by pixel) fashion over selected sample areas. The Si drift detector (VORTEX, SII NanoTechnology USA Inc., Northridge, CA, USA) used to register fluorescence photons emitted from the sample at each pixel is positioned at a right angle to the incident beam to minimize Compton scattering intensity. The $\mu$-XRD images at each pixel are obtained using an exposure time of $10 \mathrm{~s}$, regulated with a timed beam shutter, by means of a high resolution CCD camera (MAR CCD, MARUSA Co.) with $100 \mathrm{~mm}$ diameter positioned at $195 \mathrm{~mm}$ behind the sample. This allows covering a $2 \Theta$ angle up to nearly $23^{\circ}$. Evaluation of the $\mu$-XRF data is performed using the AXIL software package from the University of Antwerp [11]. The XRDUA software [12] developed and written especially for the evaluation of scanning $\mu$-XRD data is used to evaluate the diffraction patterns. The incident beam energy (E) and the experimental (geometry and detector) parameters for the $\mu$-XRD experiments are calibrated against the pattern measured for $\mathrm{Si}$ (lattice parameter= $0.543119 \mathrm{~nm}$; [13]) and values checked against XRD patterns measured for $\mathrm{LaB}_{6}$ (lattice parameter $=0.415690 \mathrm{~nm}$; ICSD data sheet 340427). Principle component analysis (PCA) on a series of 1D diffractograms (background subtracted azimuthally integrated intensities of CCD images) is performed using the PCA utility of the SIXPACK spectroscopy software [14].

The Ruprechtov site is described in [1]. A thin section of the same Ruprechtov bore core sample studied in [6] is obtained by cutting the sample, mounting it on a $25 \times 45 \mathrm{~mm}^{2}$ fused silica slide with an epoxy glue, and polishing it down to approximately a
$20 \mu \mathrm{m}$ thickness. The slide mount leads to substantial amorphous background in the XRD CCD images out to $2 \Theta$ of around $17^{\circ}$, which must be subtracted from the integrated $1 \mathrm{D}$ diffractograms.

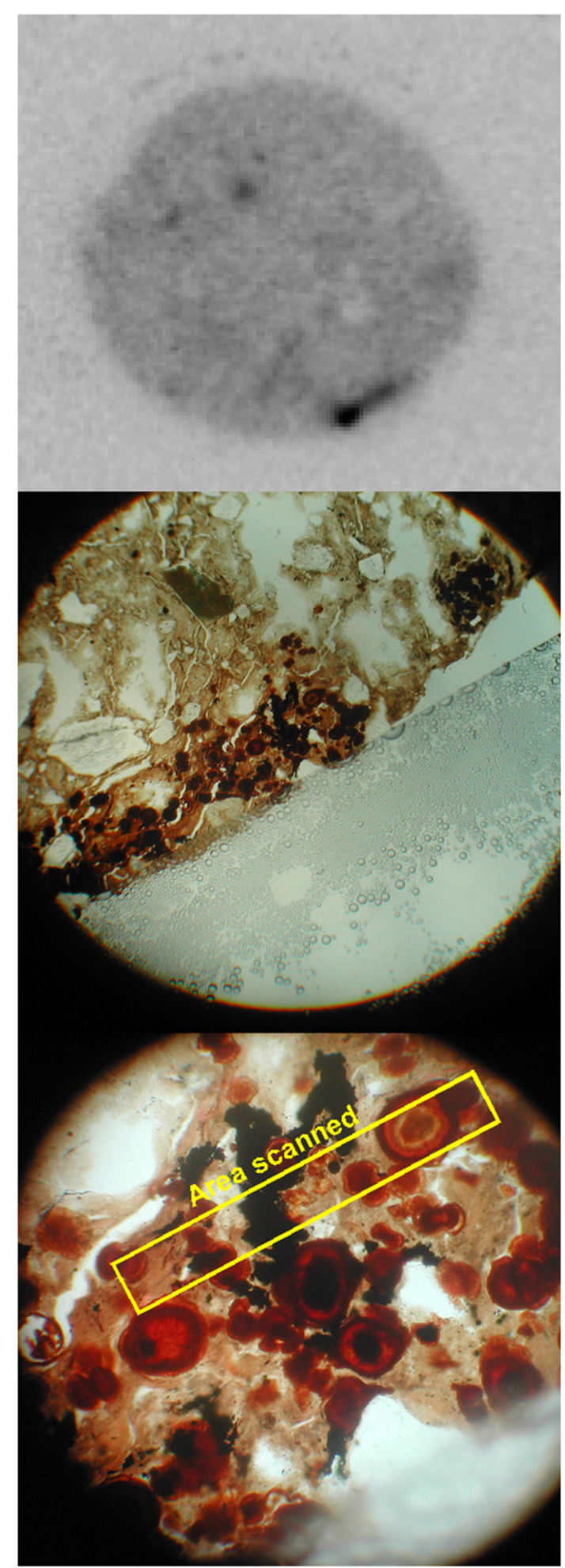

Fig. 1. From top to bottom: autoradiogram of the original bore core section with approximate $19.5 \mathrm{~mm}$ diameter, optical microscopic image of a portion of this section mounted on fused silica near the large hot spot located to the lower right of the autoradiogram, enlargement of the sample area investigated showing the scanned area of $710 \mu \mathrm{m} \times 120 \mu \mathrm{m}$. 


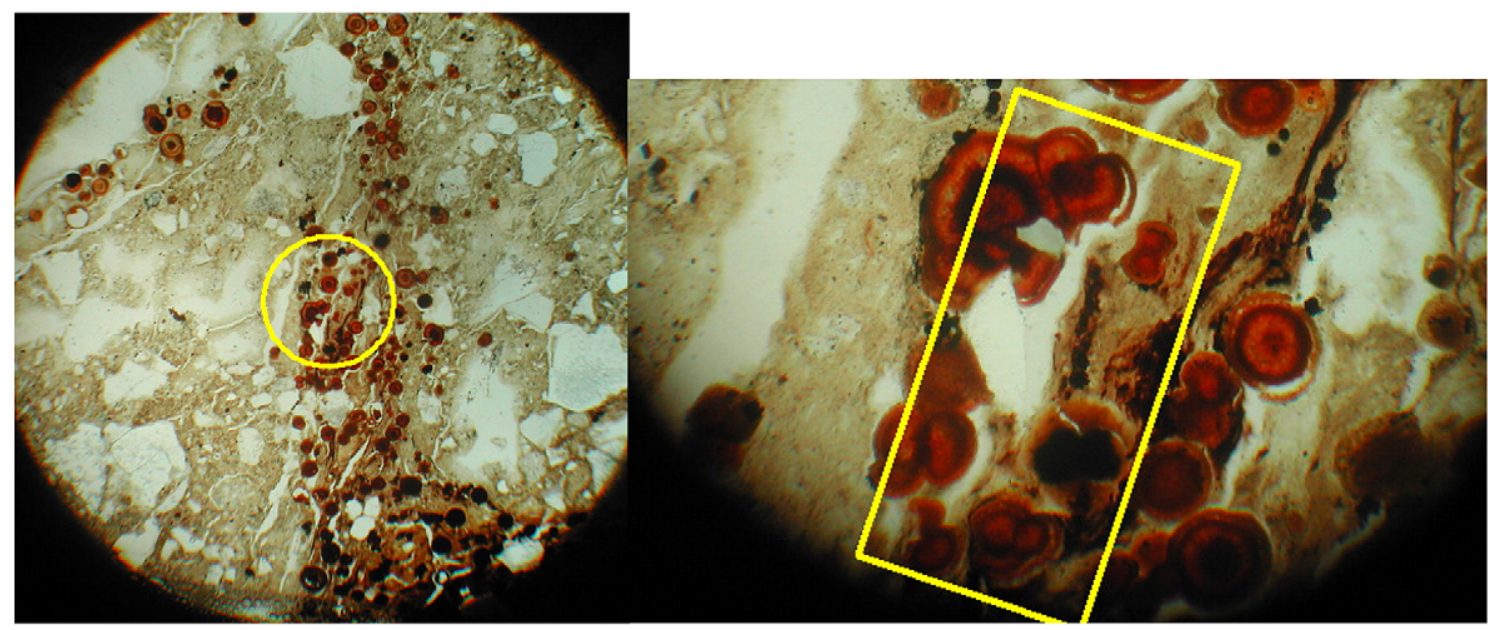

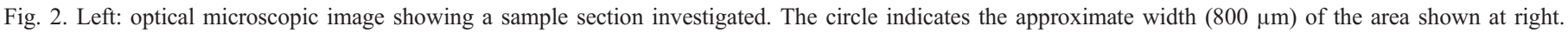
Right: the $240 \mu \mathrm{m} \times 480 \mu \mathrm{m}$ scanned area is indicated.

An autoradiogram of the original bore core section showing the U-enriched hot spots (maximum $\mathrm{U}$ concentration around $150 \mu \mathrm{g} / \mathrm{g}$ sediment) as dark areas is depicted at the top of Fig. 1. Also shown in Fig. 1 is one of the areas $(710 \mu \mathrm{m} \times 120 \mu \mathrm{m} ; 10 \mu \mathrm{m}$ step size) scanned in the experiments. Note that XRD images from the CCD camera are only recorded for the first 9 rows of pixels due to technical difficulties (exceeding the limited available data storage capacity) so that $71 \times 9$ images of the area are obtained. A second scanned area $(240 \mu \mathrm{m} \times 480 \mu \mathrm{m} ; 15 \mu \mathrm{m}$ step size) is shown in Fig. 2.

\section{Results and discussion}

Elemental distribution maps for $\mathrm{Fe}, \mathrm{As}$, and $\mathrm{U}$ are obtained by plotting background corrected fluorescence intensities for $\mathrm{Fe} \mathrm{K} \alpha$, As $\mathrm{K} \alpha$, and $\mathrm{U} L \alpha$ lines as a function of pixel position of the area scanned. The intensities are scaled in shades of black, grey, and white by assigning the pixel with the largest corresponding fluorescence intensity signal the color black, the pixel with the lowest intensity white, and scaling the remaining pixel intensities accordingly on a relative linear scale. The results for the $710 \mu \mathrm{m} \times$ $120 \mu \mathrm{m}$ area shown in Fig. 1 are depicted in Fig. 3. The large Fe nodule evident in the micrograph is clearly visible as a dark Fe area

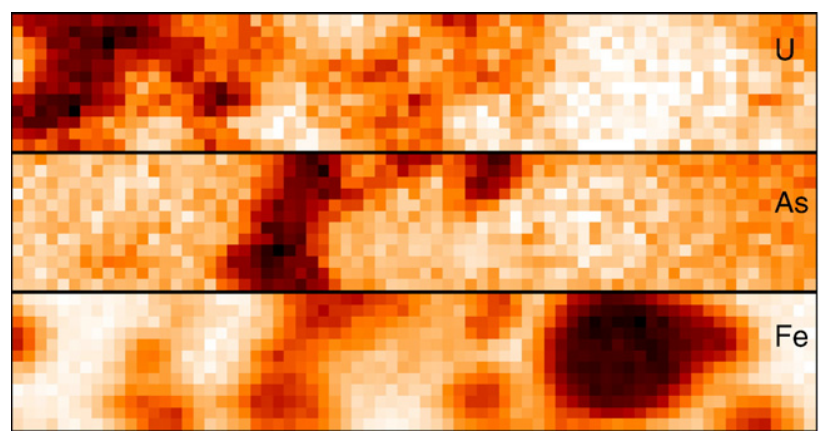

Fig. 3. Elemental distributions for Fe, As, and $U$ recorded in the $710 \mu \mathrm{m} \times$ $120 \mu \mathrm{m}$ area shown in Fig. 1 . Each pixel $10 \mu \mathrm{m} \times 10 \mu \mathrm{m}$. Counting time $=10 \mathrm{~s}$. Dark pixels represent areas of relatively high concentration and lighter pixels areas of low concentration, and white of no detectable concentration. of around $180 \mu \mathrm{m}$ in width and filling nearly the entire $120 \mu \mathrm{m}$ height of the area scanned. The As distribution is limited to the middle of the scanned area and appears associated with the $\mathrm{Fe}$ features in the mid-third section. Upon comparing the As and the $\mathrm{Fe}$ distributions in the mid-section we find the As distribution to appear shifted 1 or 2 pixels $(10-20 \mu \mathrm{m})$ to the left of that for Fe. The $\mathrm{U}$ distribution is localized to the left of the scanned area. As in our previous investigation [6], $\mathrm{U}$ is found in areas void of As and $\mathrm{Fe}$. Likewise, scanned areas with high $\mathrm{As}$ and $\mathrm{Fe} \mathrm{K} \alpha$ intensities appear as white pixels in the $\mathrm{U} L \alpha$ intensity distribution.

As an initial step in the analysis of the XRD images, the CCD images associated with selected rows or columns of pixels with high $\mathrm{Fe}$, As, or U fluorescence intensity in the element distribution maps are superimposed and their 1D diffractograms extracted by integrating the superimposed images. Sixteen pixels in the row with the highest Fe intensity (row 2, columns 48-63) are superimposed and integrated to obtain the diffractogram designated "Ferich phase", the 10 pixels with highest As intensity (row 9, columns 18-27) to yield the diffractogram "As-rich phase", and six plus seven for 13 pixels total in two rows of high $\mathrm{U}$ intensity (row 2, columns 5-10 and row 9, columns 3-9) to obtain the diffractogram "U-rich phase". The CCD images of the As-rich phase show discrete diffraction spots or grainy Debye rings. The CCD images for the Fe-rich phase exhibit homogeneous Debye powder diffraction rings, indicative of fine-grained crystallites. The superimposed CCD images for the "U-rich phase" show no significant rings but merely a few individual reflections. The 1D diffractograms for the Fe-rich, the As-rich phase, and the U-rich phase are depicted in Fig. 4 and compared to calculated diffractograms using expected d-spacing values for pyrite $\left(\mathrm{FeS}_{2} ; \mathrm{ICSD}\right.$ data sheet 15012), siderite $\left(\mathrm{FeCO}_{3}\right.$; ICSD data sheet 100678), and for arsenopyrite (AsFeS; triclinic P -1(2); ICSD data sheet 43508). We see that the $2 \Theta$ and $d$-spacing values observed in the As-rich and the Fe-rich phase diffractograms are comparable to that for pyrite and siderite, respectively. The single $2 \Theta$ peak significantly above noise level for the U-rich sample area corresponds to a d-spacing around $2.70 \AA$, corresponding to the (200) reflection for pyrite. The U-phase is apparently X-ray amorphous. There are no visible significant reflections in either the As-rich or 

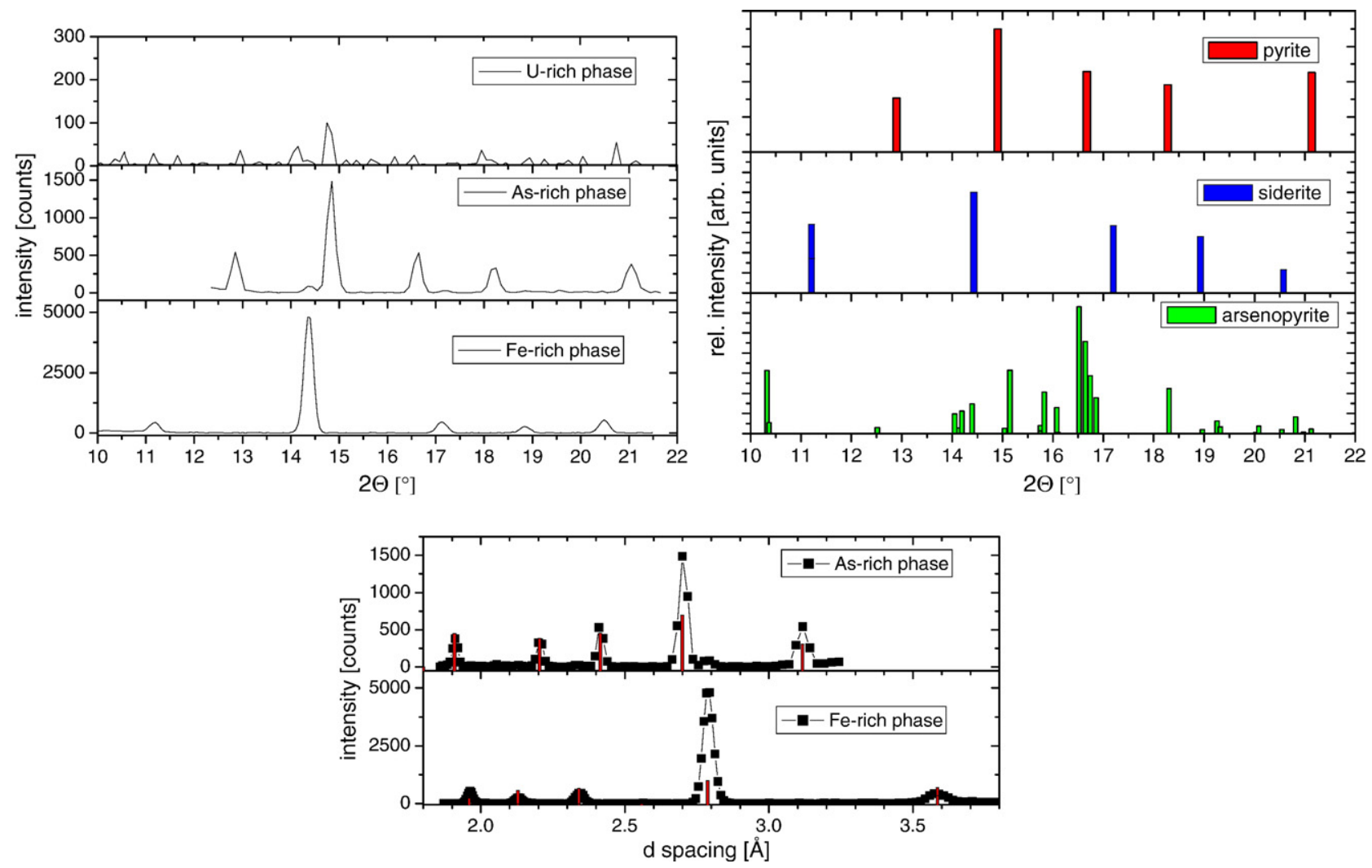

Fig. 4. 1D diffractograms as $2 \Theta$ versus intensity for selected scanned areas high in $\mathrm{U} L \alpha$, As $\mathrm{K} \alpha$, and Fe $\mathrm{K} \alpha$ fluorescence intensity, as described in the text (left). The expected $2 \Theta$ reflexes for pyrite, siderite, and arsenopyrite at $\lambda=0.07011 \AA$ are shown at right. The corresponding plots for the As-rich and Fe-rich areas as $\mathrm{d}$-spacing versus intensity are at bottom. The calculated d-spacings for pyrite and siderite are indicated as vertical bars in the As-rich and Fe-rich d-spacing versus intensity plots, respectively.

the Fe-rich phase diffractograms other than pyrite and siderite. This holds true especially in the As-rich phase diffractogram, in which we might expect to find indication of the presence of arsenopyrite.

In order to evaluate if other scanned areas of the sample contain crystalline phases other than pyrite and siderite we create XRD distribution maps for these two phases. To do this, we first select d-spacing regions characteristic for these two minerals. Then we integrate each individual CCD image recorded at every pixel, determine the background subtracted intensity for $1 \AA$ windows centered on the five reflections expected for pyrite and five reflections expected for siderite and plot these as a function of pixel position. The pyrite d-spacings used are $3.121 \AA$ (hkl $=111 ; \pm 0.05$

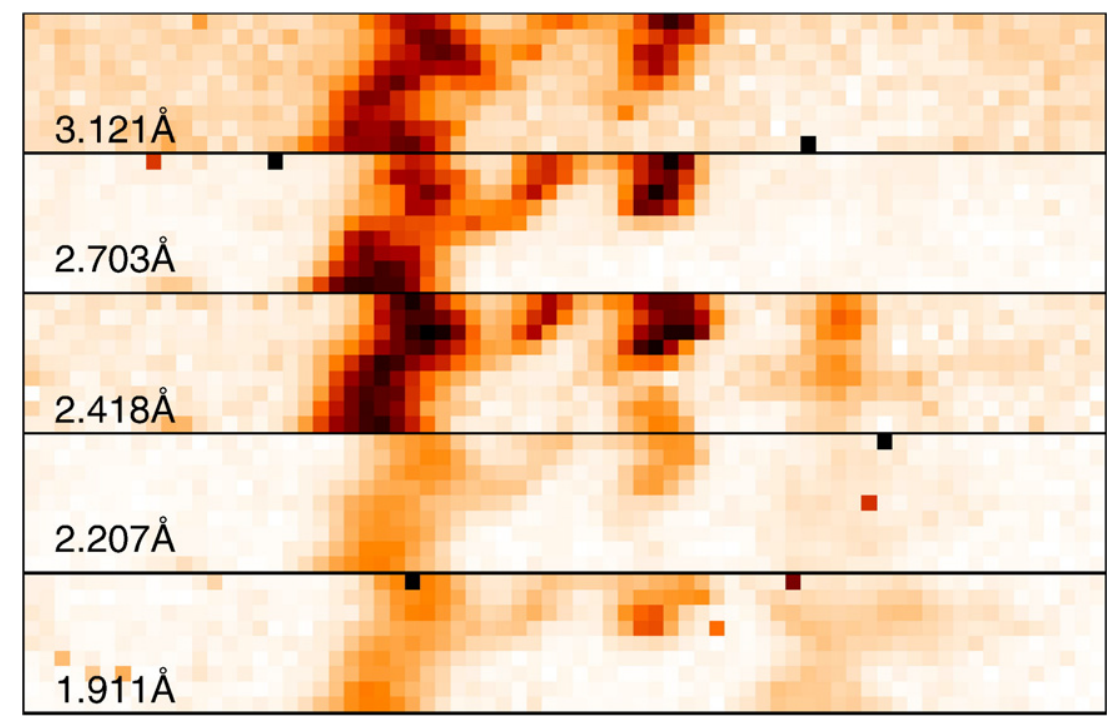

Fig. 5. Distribution of measured diffraction intensities for d-spacings indicated, which are expected reflexes for pyrite, for the top $90 \mu \mathrm{m}$ of the scanned area in Fig. 1. See text for details. 
$\AA$ d-spacing range corresponding to $12.692^{\circ}<2 \Theta>13.108^{\circ}$ at $\lambda=0.07011 \AA), 2.703 \AA\left(\mathrm{hkl}=200 ; 14.631^{\circ}<2 \Theta>15.185^{\circ}\right)$, $2.418 \AA\left(\mathrm{hkl}=210 ; 16.334^{\circ}<2 \Theta>17.029^{\circ}\right), 2.207 \AA(\mathrm{hkl}=211$; $\left.17.870^{\circ}<2 \Theta>18.705^{\circ}\right)$, and $1.911 \AA\left(\mathrm{hkl}=220 ; 20.591^{\circ}<2 \Theta>\right.$ $21.710^{\circ}$ ). The result is depicted in Fig. 5 and should essentially reflect the pyrite phase distribution. The maps from this procedure using the five reflections expected for siderite $\{3.590 \AA(\mathrm{hkl}=210$; $\left.11.052^{\circ}<2 \Theta>11.365^{\circ}\right), 2.791 \AA\left(\mathrm{hkl}=411 ; 14.175^{\circ}<2 \Theta>\right.$ $\left.14.694^{\circ}\right), 2.344 \AA\left(\mathrm{hkl}=110 ; 16.837^{\circ}<2 \Theta>17.577^{\circ}\right), 2.132 \AA$ $\left(\mathrm{hkl}=311 ; 18.492^{\circ}<2 \Theta>19.388^{\circ}\right)$, and $1.963 \AA(\mathrm{hkl}=222$; $\left.\left.20.059^{\circ}<2 \Theta>21.119^{\circ}\right)\right\}$ is depicted in Fig. 6.

We observe a general correlation between the pyrite phase distribution in Fig. 5 and the As distribution in Fig. 3. Likewise, the siderite distribution in Fig. 6 generally correlates with the large $\mathrm{Fe}$ nodule identified in the Fe distribution in Fig. 3. However, apparently this large Fe nodule is made up of a cluster of smaller siderite crystals having varying orientation. The differences in orientation affect slight dissimilarity in the individual distribution of d-spacings. We have created a normalized sum of the first four images in Fig. 6 (i.e., those for $d=3.590 \AA, 2.791 \AA$, $2.344 \AA$, and $2.132 \AA$ ) to simulate less preferred orientation and display the result at the bottom of Fig. 6. This image shows an excellent correlation to the $\mathrm{Fe}$ element distribution. We select to leave the image for the siderite with $1.963 \AA \mathrm{d}$-spacing out of the normalized sum image, as the $2 \Theta$ ranges used for this distribution show overlap with the pyrite $1.911 \AA$ reflection leading to an artefact shadowed area in the middle of the image. Overlap of the $2 \Theta$ ranges used in determining the $1.911 \AA$ and $2.418 \AA$ pyrite intensities also causes artifact shadows in their distributions in Fig. 5, which actually correspond to siderite.

We observe no dark areas in the residual images $\left(\mathrm{Chi}^{2}\right.$ as the squared difference between the measured XRD CCD image for each pixel and the sum of all the d-spacing distribution images, excluding the normalized sum image; residual not shown) clustered on or near the border to the pyrite, as we might expect if a thick enough crystalline arsenopyrite layer covering the pyrite were present. Nevertheless, we create XRD distribution maps for arsenopyrite using selected d-spacings, which do not overlap the two other minerals. As opposed to using a defined $1 \AA$ range as for the other minerals, the d-range is limited in this case to avoid overlap. The d-spacing and $2 \Theta$ ranges used are $3.846 \AA-3.946 \AA$ $\left(10.194^{\circ}<2 \Theta>10.460^{\circ}\right), 2.495 \AA-2.565 \AA\left(15.710^{\circ}<2 \Theta>\right.$ $\left.16.1537^{\circ}\right)$, and $2.020 \AA-2.100 \AA\left(19.219^{\circ}<2 \Theta>19.987^{\circ}\right)$. One can convince oneself that these ranges do not overlap with peaks for siderite or pyrite from the data shown in Fig. 4. If arsenopyrite is present, we expect particularly to find evidence for the $d=$ $3.86 \AA$ (110) reflection, as it should have significant intensity and is well isolated from reflections associated with the other two minerals (at $2 \Theta=10.3^{\circ}$ ). The resulting three images (not shown), however, lead to distributions with no identifiable structure; only scattered low intensity pixels (or noise), i.e. no indication of any arsenopyrite is observed.

The $\mathrm{Fe}, \mathrm{As}$, and $\mathrm{U}$ element distributions determined for the $240 \mu \mathrm{m} \times 480 \mu \mathrm{m}$ scanned area in Fig. 2 are depicted in Fig. 7. We find one area with relatively high As concentration (As K $\alpha$ intensities with up to 90 counts/s. We compare this to the areas with high Fe K $\alpha$ intensities with 50-65 counts/s) and what appears to be a hot spot in the $\mathrm{U}$ distribution; however, this particular pixel is associated with only around 25 counts/s.

We repeat making XRD distribution maps for pyrite and siderite for this scanned area using the exact same characteristic $\mathrm{d}$ spacings ( $\pm 0.05 \AA$ and corresponding $2 \Theta$ ranges) as before. The results are shown in Fig. 8. The distribution images for the pyrite d-spacings $3.121 \AA$ and $2.207 \AA$ have been omitted, as they showed no identifiable structure. The distribution image for the siderite d-spacings $1.963 \AA$ is omitted because of its overlap with

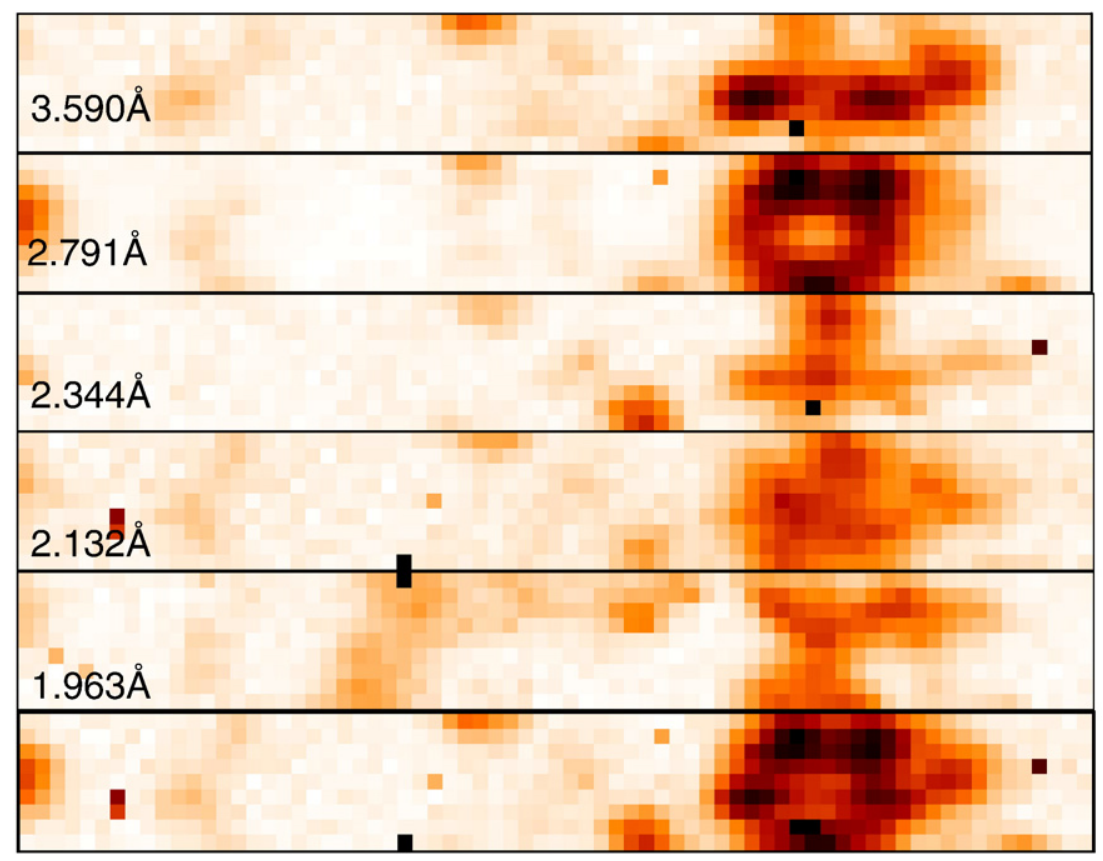

Fig. 6. Distribution of measured diffraction intensities for d-spacings indicated, which are expected reflexes for siderite. The lowest image is a normalized sum of the first four images. See text for details. 


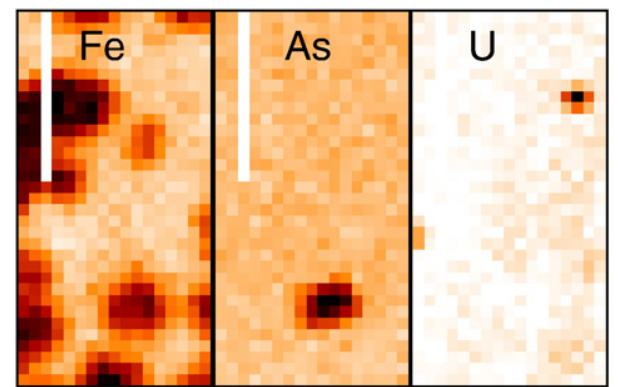

Fig. 7. Fe, As, and $U$ distribution images for the $240 \mu \mathrm{m} \times 480 \mu \mathrm{m}$ scanned area indicated in Fig. 2. Each pixel is $15 \mu \mathrm{m} \times 15 \mu \mathrm{m}$. The white pixels result from an injection of the DORIS III ring during the scan. Pixel intensities are normalized to the ring current.

the pyrite $1.911 \AA$ reflection. Also shown in Fig. 8 are the normalized sum images of the three pyrite $\mathrm{d}$-spacing distributions and the four distributions for siderite. We find the greatest similarity between the elemental distributions in Fig. 7 and these sum images. Similar to our observation for the siderite distribution maps in Fig. 6, comparison of the Fe distribution in Fig. 7 with the d-spacing distributions in Fig. 8 indicates the Fe phases to be made up of clusters of smaller crystallites with varying orientation. The differences in orientation affect slight dissimilarity in the individual distribution of d-spacings so that the normalized sum images best reflect the elemental distributions. Similar observations of $\mathrm{Fe}$ framboids comprised of clusters of crystallites with varying orientation have been reported $[15,16]$. Further comparison of these mineral phase distributions with the elemental distributions shows that the As-rich area towards the middle of the lower half of the area scanned is associated with pyrite. The siderite distribution mirrors the Fe distribution, with the exception of the nodule associated with pyrite. We also create an arsenopyrite distribution map using the same $\mathrm{d}$-spacing and $2 \Theta$ ranges as before. Again we obtain maps containing only noise. There is no evidence for the presence of any arsenopyrite. When we superimpose CCD images associated with selected pixels with high $\mathrm{Fe}$, As, or U fluorescence intensity in the element distribution maps and extract their associated 1D diffractograms, we find only diffraction peaks corresponding to pyrite and siderite.

We use two different chemometric methods to determine if any additional crystalline mineral phase other than pyrite and siderite in the sample area scanned is present, which does not show up in the phase mapping procedure: principle component analysis and unsupervised classification (USC, [17]). The USC method is regularly used in remote sensing applications and is a statistical approach to find clusters in a multidimensional feature space. The clusters (i.e., n-dimensional vectors) are expected to represent significantly different measures of a sample, the meaning of which is a matter of interpretation by the analyst. In the USC procedure, one defines the number of expected features or so-called classes, in our case the number of different phases assumed to be present in the sample, and an initial guess for class positions inside feature space. Typically initial class positions are class centers along the feature space diagonal or positions selected arbitrarily from data by chance. An iterative procedure is then used to find clusters such that any vector of the input data is compared to the given classes using a similarity measure. We use the Euclidian distance as a similarity measure. With each iteration step the input vectors are bound to the class having the strongest similarity. After each data point is connected to a given class, every class center is shifted with respect to the connected data points. We use the center of mass. The binding of data points to given classes is then removed and the similarities for each point in feature space recalculated.

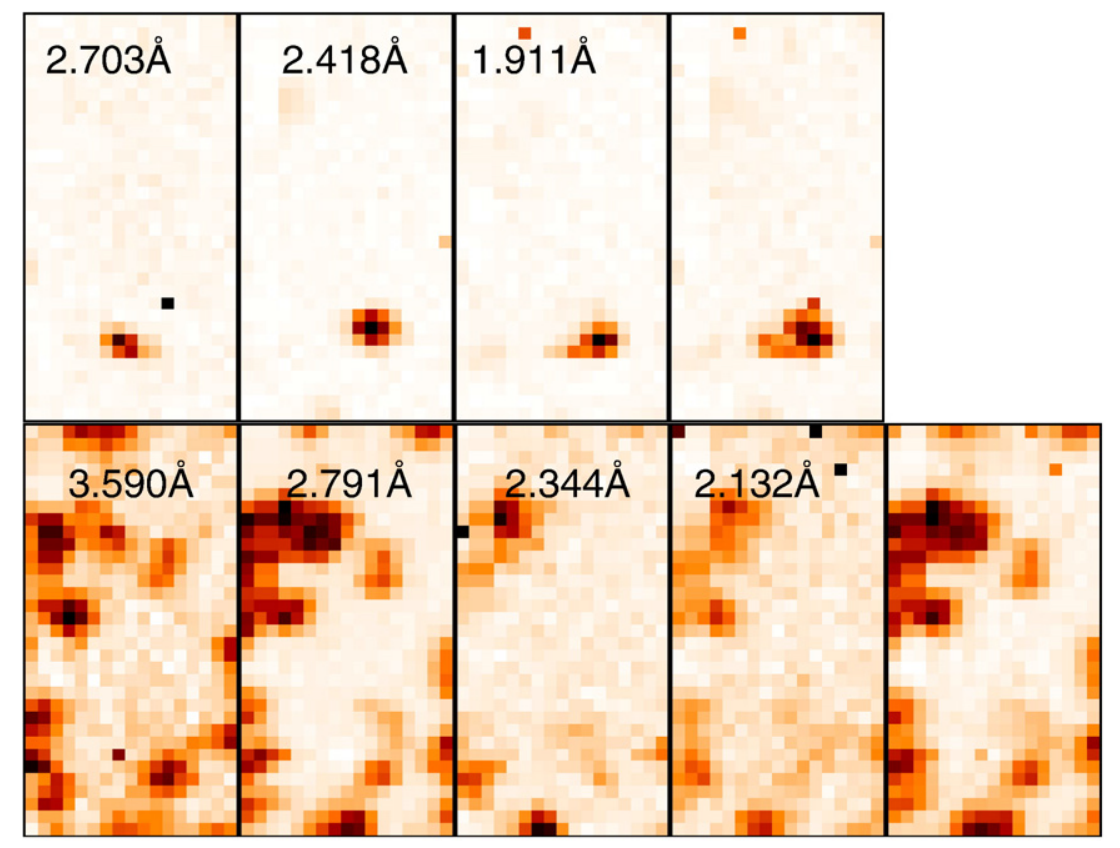

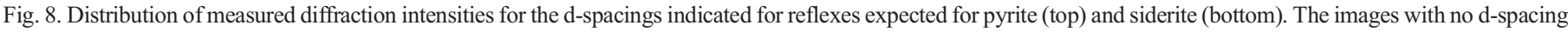

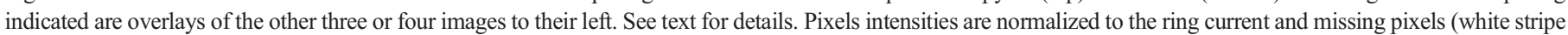
from an injection of the DORIS III ring seen in Fig. 7) is arbitrarily filled with intensities from the left lying pixels. 
The iterative process is repeated until a predefined termination criterion is reached. In this way individual measurements or an area image (or image stack) can be classified according to clusters, thereby generating a classification map. Finally, in order to interpret the data, the differing regions in the classification map are related to meaningful categories.

For USC of the area scanned in Fig. 1, we use 635 integrated 1D diffractograms extracted from the $71 \times 9 \mathrm{CCD}$ images and removing six of the 641 pixels having noticeable fault. The diffractograms are initially divided into $212 \Theta$ ranges, indicated as shaded bars in Fig. 9f. We use the average signal intensity of each $2 \Theta$ range and apply USC using five classes. Using the classi-
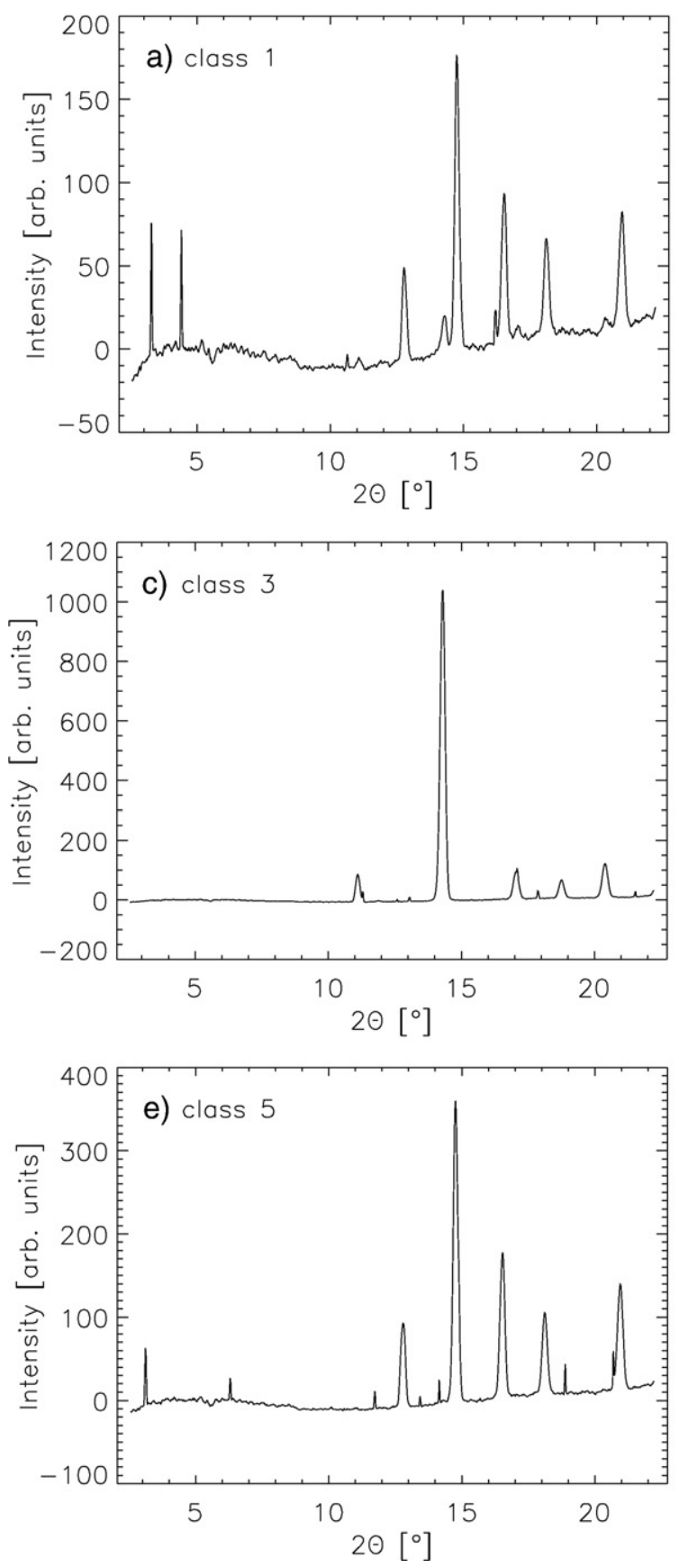

fication results we obtain with the averaged $2 \Theta$ ranges, the corresponding diffractograms of the five classes are derived. These are depicted in Fig. 9a-e. When we compare these results with the expected $2 \Theta$ values in Fig. 4 we find that classes 1 and 5 exhibit basically the same diffraction pattern and reflections lie at $2 \Theta$ values expected for pyrite. The classes 2,3 , and 4 show the same peak positions and these lie at $2 \Theta$ values expected for siderite. We find neither evidence for significant amounts of arsenopyrite nor for any other diffracting phase. Note that this exercise is intended to ascertain if classes exist, which have peaks in addition to those for pyrite and siderite; it is not intended to evaluate any differences in diffraction peak intensities or widths.
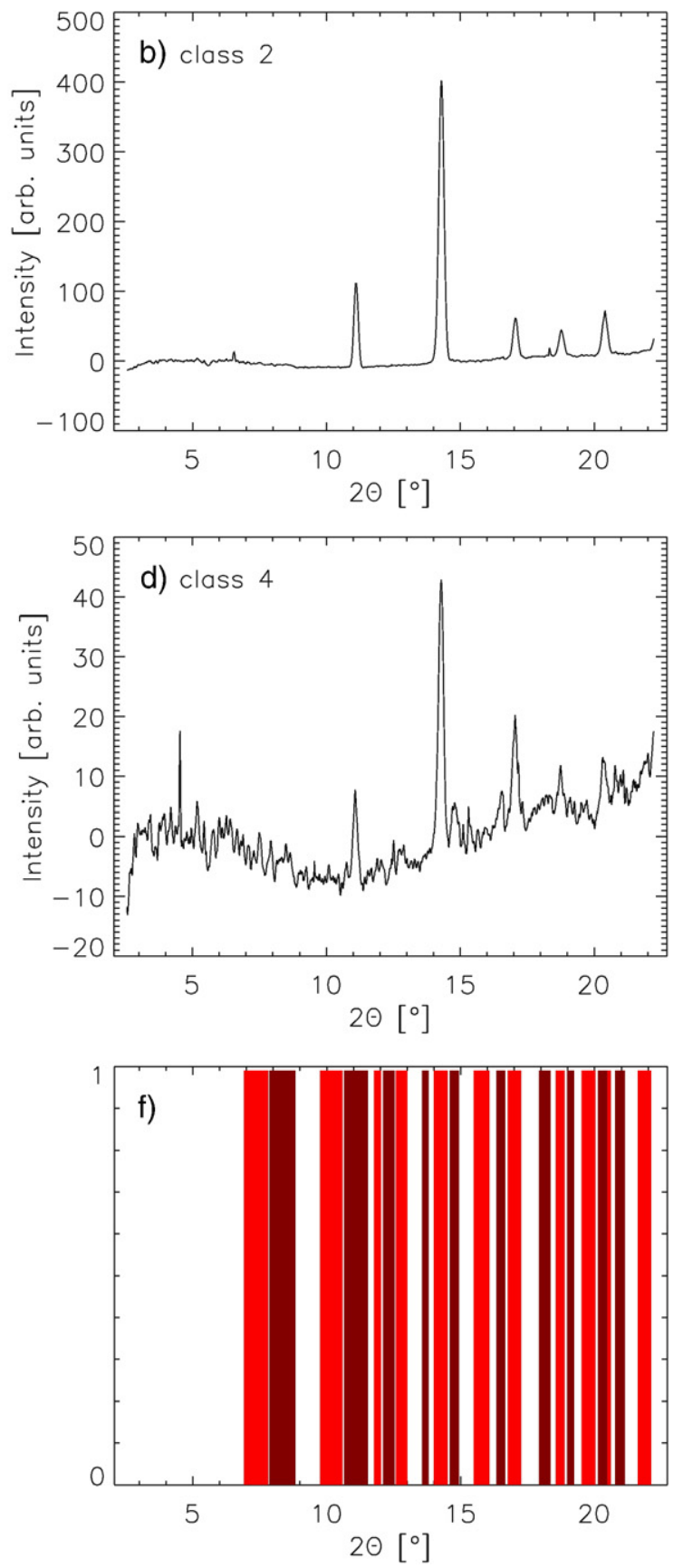

Fig. 9. a-e) Diffractograms of the five classes derived from USC applied to 1D XRD data of the area scanned shown in Fig. 1. f) Shaded areas indicate the 21 average signal intensities of $2 \Theta$ used in the initial USC procedure. See text for details. 


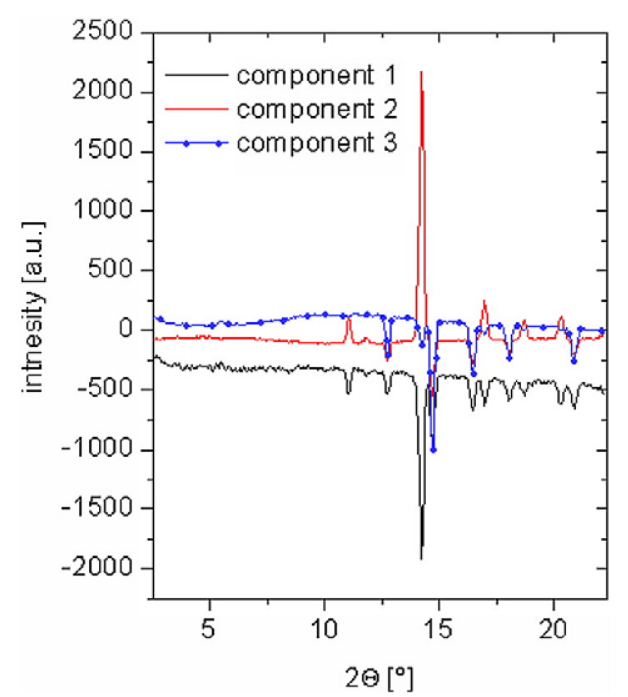

Fig. 10. First three components found in PCA of 1D diffractograms for a row of pixels in the area scanned in Fig. 1.

We perform PCA on a row of pixels (68 of 71 pixels, as three data points are removed due to their having outlier intensity spikes) using the same $1 \mathrm{D}$ data as in the USC procedure. The eigenvalues from the PCA results show that components 1 through 3 become progressively less important and virtually unimportant (i.e., approach zero) for four components. A plot of the cumulative variance versus number of components (not shown) shows a break in the slope at three components. These results indicate that the minimum number of components in the system is three. Inspection of the three PCA components (Fig. 10) reveals that they have positive or negative peak intensities at $2 \Theta$ positions corresponding to those expected for pyrite and siderite. No other reflections, especially near $10.3^{\circ}$ expected for arsenopyrite, are observed. There is not any indication of a phase other than pyrite and siderite.

We find no evidence from our spatially resolved, scanning diffraction data for the presence of arsenopyrite in the sample; only diffraction patterns for the minerals pyrite and siderite are observed. Arsenopyrite has been previously identified from its As K-edge XANES signature [6] and from the observed linear dependence between $\mathrm{Fe}$ and $\mathrm{As}(0)$ distributions in As-rich coatings of framboidal Fe nodules in the sediment [7]. Nevertheless, we find no diffraction peaks for arsenopyrite. Not even attempts to find minority diffracting phases in the sample using statistical methods (PCA or USC) are successful. We note, however, that to our knowledge this is the first reported application of USC to evaluate scanning $\mu$-XRD data and consider this approach highly recommendable when searching for minority diffracting phases.

\section{Conclusions}

That we do not observe arsenopyrite in our $\mu$-XRD data, although we have spectroscopic evidence (from both XANES and $\operatorname{As}(0)$-Fe correlation) that this mineral is present, can mean one of two things: either the amount of arsenopyrite present is too small to be identified or the crystallites are so small or amorphous that the associated Bragg reflections are not observed. As other groups report that $\mu$-XRD is able to identify phases comprising $<1 \%$ of the bulk sample when the minor phase is positioned under the focused beam [18], we do not believe that the amount is too small but rather we are dealing with the latter, very small crystallites or amorphous material. The arsenic in the sample is observed to be associated with pyrite, as there is a positive correlation between the distribution of As in the elemental and the distribution of pyrite in the XRD mineral phase maps. We also observe As coated Fe framboids in previous studies with high spatial resolution [7]. These observations may indicate that arsenopyrite is present as thin amorphous or nanocrystalline coating on pyrite framboids, which formed secondary to the original framboid nodules. We do not believe that As is simply presently incorporated as a minor constituent in pyrite, because of the observed linear dependence between $\mathrm{Fe}$ and $\operatorname{As}(0)$ distributions in the sediment. If As is a minor constituent, then this linear dependence would indicate that the trace As level is constant over all areas of the sediment studied, which seems unlikely.

Because we observe pyrite and siderite in the same sediment, we can assume that the $\mathrm{pH}$ was near neutral during formation of these minerals. We can therefore refine our proposed simplified reaction for the mechanism of uranium immobilization in the sediment, where arsenopyrite reduces dissolved U(VI) leading to precipitation of less-soluble U(IV), using doubly deprotonated arsenic acid $\left(\mathrm{pK}_{\mathrm{a} 2}=6.8\right)$ for near neutral $\mathrm{pH}$ conditions:

$$
\begin{aligned}
& 13 \mathrm{UO}_{2}^{2+}+2 \mathrm{FeAsS}+16 \mathrm{H}_{2} \mathrm{O} \leftrightarrow 13 \mathrm{UO}_{2}(\mathrm{am})+2 \mathrm{Fe}^{2+} \\
& +2 \mathrm{HAsO}_{4}^{2-}+30 \mathrm{H}^{+}+2 \mathrm{SO}_{4}^{2-}
\end{aligned}
$$

\section{Acknowledgments}

We thank HASYLAB for awarding us beamtime, E. Sobolla for the preparation of the thin sections, J. Römer for the autoradiographic measurements, and D. Bosbach for fruitful discussion of results.

\section{References}

[1] U. Noseck, Th. Brasser, Radionuclide Transport and Retention in Natural Rock Formations. Ruprechtov Site (GRS-218), Gesellschaft für Anlagenund Reaktorsicherheit (GRS) mbH, Braunschweig, 2006.

[2] U. Noseck, Th. Brasser, P. Raijlich, M. Hercik, A. Laciok, Mobility of uranium in tertiary argillaceous sediments - a natural analogue study, Radiochim. Acta 92 (2004) 797-804.

[3] U. Noseck, Th. Brasser, W. Pohl, Tertiäre Sedimente als Barriere für die U-/Th-Migration im Fernfeld von Endlagern (GRS-176), Gesellschaft für Anlagen- und Reaktorsicherheit (GRS) mbH, Braunschweig, 2002.

[4] U. Noseck, Th. Brasser, A. Laciok, M. Hercik, F. Woller, Uranium migration in argillaceous sediments as analogue for transport processes in the far field of repositories (Ruprechtov site, Czech Republic), in: B. Merkel, et al., (Eds.), Uranium in the Aquatic Environment, Springer, Heidelberg, 2002.

[5] W. Miller, R. Alexander, N. Chapman, I. Mc Kinley, J. Smellie, Geological Disposal of Radioactive Wastes \& Natural Analogues, Pergamon, Amsterdam, 2000.

[6] M.A. Denecke, K. Janssens, K. Proost, J. Rothe, U. Noseck, Confocal micro$\mathrm{XRF}$ and micro-XAFS studies of uranium speciation in a tertiary sediment from a waste disposal natural analogue site, Environ. Sci. Technol. 39 (2005) 2049-2058.

[7] M.A. Denecke, A. Somogyi, K. Janssens, R. Simon, K. Dardenne, U. Noseck, Microanalysis (micro-XRF, micro-XANES and micro-XRD) of a 
tertiary sediment using synchrotron radiation, Microsc. Microanal. 13 (2007) $165-172$.

[8] M.A. Denecke, K. Janssens, B. Brendebach, W. De Nolf, G. Falkenberg, J. Rothe, R. Simon, A. Somogyi, B. Vekemans, U. Noseck, Confocal $\mu-X R F$ $\mu$-XAFS, and $\mu$-XRD studies of sediment from a nuclear waste disposal natural analogue site and fractured granite following a radiotracer migration experiment, in: B. Hedman, B.P. Pianetta (Eds.), X-ray Absorption Fine Structure-XAFS13, American Institute of Physics, Melville, NY, 2007, pp. 187-189.

[9] G. Falkenberg, O. Clauss, Th. Tschentscher, X-ray Optics for the Microfocus Beamline L. http://hasyweb.desy.de/science/annual_reports/2001_report/ part1/intern/5720.pdf.

[10] R. Huang, D.H. Bilderback, Single-bounce monocapillaries for focusing synchrotron radiation: modeling, measurements and theoretical limits, J. Synchrotron Radiat. 13 (2006) 74-84;

G. Falkenberg, K. Rickers, D.H. Bilderback, R. Huang, A Single-bounce Capillary for Focusing of Hard X-rays. (http:/hasyweb.desy.de/science/ annual_reports/2003_report/part1/intern/11062.pdf).
[11] B. Vekemans, K. Janssens, L. Vincze, F. Adams, P. Van Espen, Analysis of $\mathrm{X}$-ray spectra by iterative least squares (AXIL): new developments, X-ray Spectrometry 23 (1994) 278.

[12] http: \xrdua.ua.ac.be.

[13] Nation Institute of Standards and Technology, Standard Reference Material 640c.

[14] SIXPACK software download and information: http://www-ssrl.slac. stanford.edu/ swebb/sixpack.htm.

[15] H. Ohfuji, D. Rickard, M.E. Light, M.B. Hursthouse, Structure of framboidal pyrite: a single crystal diffraction study, Eur. J. Mineral. 18 (2006) 93-98.

[16] H. Ohfuji, A.P. Boyle, D.J. Prior, D. Rickard, Structure of framboidal pyrite: an electron backscatter diffraction study, Am. Mineral. 90 (2005) 1693-1704.

[17] see, e.g.: R.O. Duda, P.E. Hart, Pattern Classification and Scene Analysis, Wiley, New York, 1973.

[18] R.L. Flemming, K.A. Salzsauler, B.L. Sherriff, N.V. Sidenko, Identification of scorodite in fine-grained, high-sulfide arsenopyrite mine-waste using micro X-ray diffraction, Can. Min. 43 (2005) 1243-1254. 